\title{
FLEXURAL FRACTURE RESPONSE OF A NOVEL IRON CARBONATE MATRIX - GLASS FIBER COMPOSITE AND ITS COMPARISON TO PORTLAND CEMENT-BASED COMPOSITES
}

\author{
Sumanta Das ${ }^{1}$, Alyson Hendrix ${ }^{2}$, David Stone ${ }^{3}$, Narayanan Neithalath ${ }^{4, *}$ \\ ${ }^{1}$ Graduate Student, School of Sustainable Engineering and the Built Environment, Arizona State \\ University, Tempe, AZ, USA, e-mail: Sumanta.Das@asu.edu \\ ${ }^{2}$ Undergraduate Student, School of Sustainable Engineering and the Built Environment, Arizona State \\ University, Tempe, AZ, USA, e-mail: akhendr1@asu.edu \\ ${ }^{3}$ CEO, Iron Shell LLC, Tucson, AZ, USA, e-mail: dajstone@gmail.com \\ 4,* Corresponding Author; Associate professor, School of Sustainable Engineering and the Built \\ Environment, Arizona State University, Tempe, AZ, USA, e-mail: Narayanan.Neithalath@asu.edu
}

\section{ABSTRACT}

This paper explores the fracture properties of a novel and sustainable glass-fiber reinforced composite, the matrix for which is formed through the aqueous, anoxic, room-temperature carbonation of (waste) metallic iron powder along with other minor ingredients. A comparison of the properties of this binder with ordinary Portland cement pastes, which constitutes one of the most common and economic ceramic matrices is also provided. The iron-based binder system exhibits fracture parameters (fracture toughness, $\mathrm{K}_{\mathrm{IC}}{ }^{\mathrm{S}}$ and critical crack tip opening displacement, $\mathrm{CTOD}_{\mathrm{C}}$, determined using two parameter fracture model, TPFM) that are significantly higher when compared to those of the OPC systems in both the unreinforced and glass fiber reinforced states. The beneficial influence of the unreacted metallic iron particles of large aspect ratio, on the fracture parameters of iron-based binders are elucidated. The strain energy release rates show trends that are in line with the fracture parameters from TPFM. The elastic and inelastic components of strain energy release rate are separated in an effort to capture the fundamental toughening mechanisms in these systems. The fracture parameters determined using a non-contact, digital image correlation technique are found to relate well to those obtained from TPFM.

Key words: Iron carbonate, Fibers; Particle reinforcement; Fracture toughness; Digital Image Correlation (1) 7 8 9 0 


\subsection{INTRODUCTION}

32 Ordinary Portland Cement (OPC)-based materials (in particular, conventional cement concretes) are among the most common and cheapest ceramic matrices that are widely used for buildings and infrastructural applications. It is well recognized that OPC production is a significant emitter of $\mathrm{CO}_{2}$, a major greenhouse gas (GHG), into the atmosphere which is responsible for the global warming [1-6]. The global concrete industry has embraced the idea of sustainability in construction through the use of waste/recycled materials such as fly ash, blast furnace slag, and limestone powder as supplementary cementitious materials in concrete and thus reduce the scale of OPC use [7-11]. Several nonconventional means of developing novel and sustainable matrix materials for infrastructural composites are also on-going. This paper reports on one such material that has been recently developed by the authors that utilizes the anoxic carbonation of (waste) metallic iron powder at ambient temperature and pressure, which has been shown to yield beneficial mechanical properties so as to be used as a structural binder [12]. This novel binder system provides multiple environmental benefits through trapping of $\mathrm{CO}_{2}$ emitted from industrial operations, utilization of a waste material (iron powder) that is otherwise land-filled, and a reduction in OPC production/use. Establishing the performance of this novel binder system with due modifications as needed (including the use of fiber reinforcement) is expected to facilitate applications such as building envelope components (e.g., exterior wall panels), precast elements, architectural claddings, as well as in electrically conductive ceramic composite applications. In the United States alone, about 3 million tons of waste iron powder is available that can be beneficially utilized for such specialized applications.

One of the major drawbacks of ceramic matrices in general and cementitious matrices in particular relate to their low toughness. In addition, these low-toughness ceramics lose a significant portion of their strength because of service-related damage such as crack growth under static load or cyclic fatigue. Thus, enhancing the toughness of these materials contributes to minimization and control of strength loss. In the synthesis of the iron-based binder, metallic iron powder is carbonated only to a small fraction (necessitated by limitations in reaction kinetics [12]), which results in the presence of

57 large amounts of residual metallic powder in the microstructure. The presence of this phase, a significant fraction of which is elongated, will likely render notable increase in the toughness of this

59 binder because of the energy dissipation by plastic deformation [13] imparted by the metallic 60 particulate phase. In addition, the matrix contains other processing additives including harder fly ash 61 particles, softer limestone particles, and ductile clayey phases which influence the overall fracture 
performance of the novel binder significantly. The performance of glass fiber reinforcement in ironbased and OPC binder systems are also explored so as to investigate the synergistic influence of unreacted metallic iron particles in the matrix and the fiber reinforcement on the properties of interest. Center-point cyclic flexural tests on single-notched beams are carried out to determine the critical stress intensity factor $\left(\mathrm{K}_{\mathrm{IC}}{ }^{\mathrm{S}}\right)$ and the critical crack tip opening displacement $\left(\mathrm{CTOD}_{\mathrm{C}}\right)$ using the well-accepted two parameter fracture model (TPFM). The differences in fracture behavior between the iron-based binder and the traditional OPC binder are also quantified using R-curves. Additionally, the use of digital image correlation (DIC) is explored as a non-contact means of extracting the fracture parameters of ironbased binders.

\subsection{EXPERIMENTAL PROGRAM}

\subsection{Materials, Mixtures and Specimen Preparation}

The major starting material used in this study is a waste metallic iron powder with a median particle size of $19.03 \mu \mathrm{m}$, obtained from an industrial shot-blasting operation. The iron particles are elongated and angular in shape; while influencing the rheological properties of the fresh mixture, angular shape also provides benefits related to increased reactivity owing to the higher surface-to-volume ratio of the particles. Some minor ingredients such as Class F fly ash and metakaolin conforming to ASTM C 618, and limestone powder (median particle size of $0.7 \mu \mathrm{m}$ ) conforming to ASTM C 568 were also used in the binder synthesis [12]. Fly ash provides a silica source for the reactions (to potentially facilitate iron silicate complexation [14]), while the fine limestone powder provides nucleation sites. Metakaolin imparts cohesiveness to the paste mixtures because of its clayey origins. In the process of iron carbonation, water only serves as an agent of mass-transfer and does not as such chemically participate in the reactions. Minimization of water demand, yet keeping the consistency and cohesiveness of the mixture was achieved through the use of metakaolin. An organic reducing agent/chelating agent for metal cations (oxalic acid, in this case) was also used. Commercially available Type I/II OPC conforming to ASTM C 150 was used to prepare conventional cement pastes that were used as the baseline system to compare the properties of the novel iron-based binder systems. The chemical compositions of OPC, fly ash and metakaolin can be found in our previous publications $[11,15]$. Particle size distributions for iron powder, fly ash, metakaolin, limestone and OPC, determined using dynamic light scattering, are shown in Figure 1. The iron powder is coarser than all other ingredients used here. While the quantified data presented in this paper could vary depending on the fineness of the iron powder, the general trends and mechanisms remain the same. 


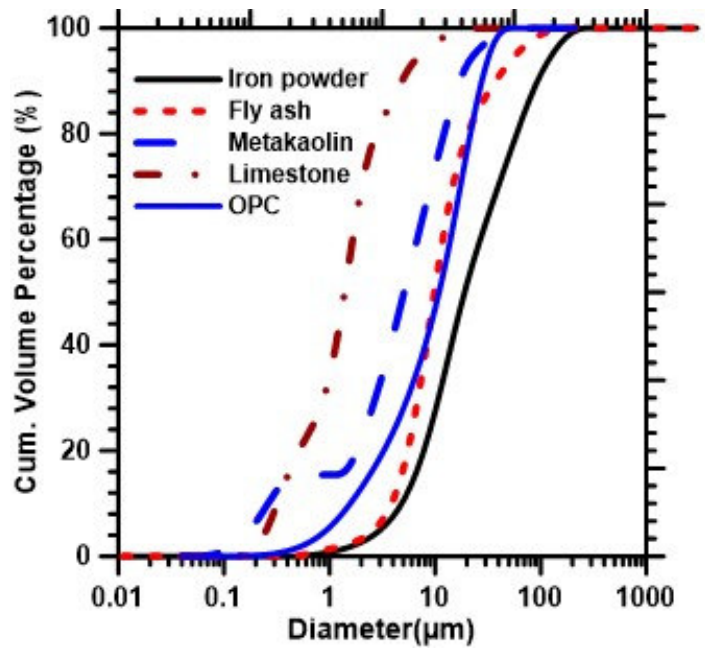

Figure 1: Particle size distribution of metallic iron powder, OPC, Fly ash, metakaolin and limestone powder

The powder fraction of the iron-based binder mixture used in this study consists of $60 \%$ iron powder, $20 \%$ fly ash, $8 \%$ limestone, $10 \%$ metakaolin, and $2 \%$ organic acid by mass. This combination demonstrated the highest compressive strength and lowest porosity among a series of trial mixtures prepared as part of material design studies [12]. The mixing procedure involves initial dry mixing of all the starting materials and then adding water to obtain a uniform cohesive mixture. A mass-based waterto-solids ratio $(\mathrm{w} / \mathrm{s})_{\mathrm{m}}$ of 0.24 was used to attain a cohesive mix, which also was arrived at based on several preliminary studies [12]. Since the carbonation process of iron does not incorporate water in the reaction products as hydrates, the $(\mathrm{w} / \mathrm{s})_{\mathrm{m}}$ used is primarily based on the criteria of obtaining desired workability.

Prismatic specimens of size $127 \mathrm{~mm}$ (length) x $25.4 \mathrm{~mm}$ (depth) x $25.4 \mathrm{~mm}$ (width) were prepared in polypropylene molds and immediately placed inside clear plastic bags filled with $100 \% \mathrm{CO}_{2}$ in room temperature inside a fume hood. The samples were demolded after 1 day of carbonation in order to attain enough strength so as to strip the molds without specimen breakage. After demolding, the beams were placed again in a $100 \% \mathrm{CO}_{2}$ environment for another 5 days. The bags were refilled with $\mathrm{CO}_{2}$ every 12 hours or so to maintain saturation. After the respective durations of $\mathrm{CO}_{2}$ exposure, the samples were placed in air at room temperature to allow the moisture to evaporate for 4 days. These $\mathrm{CO}_{2}$ and moisture exposure durations are considered in this study because the mechanical properties demonstrated insignificant changes beyond these curing times. It can be safely assumed that, for the specimen sizes evaluated here, these durations result in kinetic carbonation limits, and further 
carbonation cannot be achieved without changes in process conditions (e.g., temperature or pressure).

117 Companion OPC mixtures of the same size as mentioned above were prepared with a water-to-cement ratio $(\mathrm{w} / \mathrm{cm})$ of 0.40 , which is common for moderate-strength concretes in many buildings and infrastructural applications. The $(\mathrm{w} / \mathrm{s})_{\mathrm{m}}$ ratios used are different for both the iron-based and OPC binders because of the differences in the function of water in these binder systems. For the iron-based binders,

121 the focus is on obtaining desirable workability and moldability, while for the OPC-based binder, the $\mathrm{w} / \mathrm{cm}$ used corresponds to that used for most cementitious systems. The OPC beams were demolded after 1 day and were kept in a moist chamber $\left(>98 \% \mathrm{RH}\right.$ and $\left.23 \pm 2{ }^{\circ} \mathrm{C}\right)$ for a total of 28 days. The fiberreinforced binders were prepared by adding $0.5 \%$ and $1.0 \%$ glass fibers $(25 \mu \mathrm{m}$ diameter and $10 \mathrm{~mm}$ long) by volume to the blends while mixing. The fiber reinforced iron-based and the OPC binders were cured in the same way as their non-reinforced counterparts.

\subsection{Determination of Flexural Strength and Fracture Parameters}

128 The flexural strengths of both iron-based and OPC binders were determined using standard center-point loading as per ASTM C293/293M-10, on beams having a span of $101.6 \mathrm{~mm}$. The fracture properties, viz., the critical stress intensity factor $\left(\mathrm{K}_{\mathrm{IC}}{ }^{\mathrm{S}}\right)$ and the critical crack tip opening displacement $\left(\mathrm{CTOD}_{\mathrm{C}}\right)$, were determined from three-point bending tests on notched beams using the two-parameter fracture model (TPFM) $[16,17]$ as shown in Figure 2(a). For each mixture four replicate beams were tested. The notch depth was $3.8 \mathrm{~mm}$ (corresponding to a notch depth-to-beam depth ratio of 0.15 ). The beams were tested in a crack mouth opening displacement (CMOD)-controlled mode (CMOD acting as the feedback signal) during the loading cycles and in a load-controlled mode during the unloading cycles.

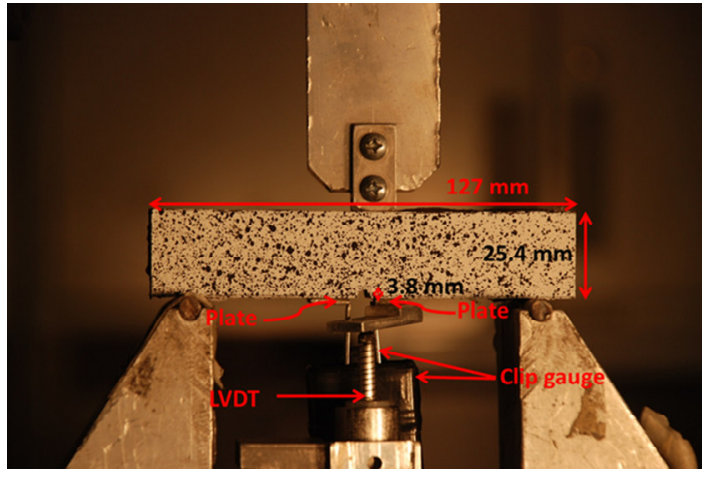

(a)

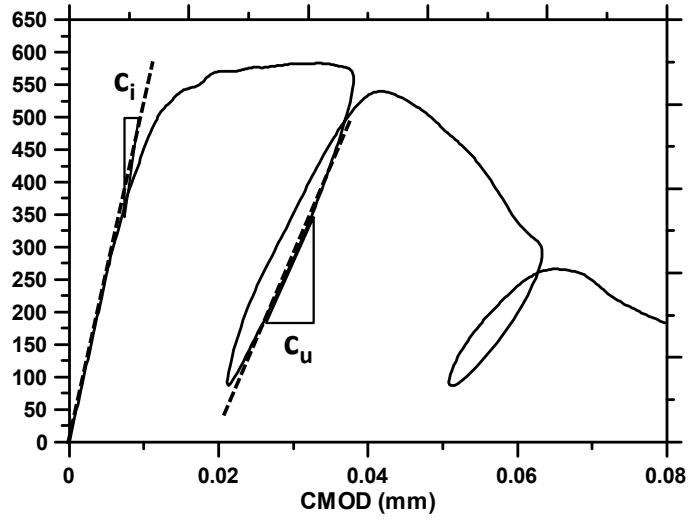

(b)
Figure 2: (a) Experimental setup for the TPFM test, and (b) a typical load-CMOD plot showing the loading and unloading compliances 
The TPFM involves the use of the loading and unloading compliances, peak load, specimen and notch geometries, and a geometry correction factor, to determine the values of $\mathrm{K}_{\mathrm{IC}}{ }^{\mathrm{S}}$ and $\mathrm{CTOD}_{\mathrm{C}}$. A typical loadCMOD plot is shown in Figure 2(b) with the loading and unloading compliances. The steps used in TPFM to determine the fracture parameters and the relevant mathematical operations are adequately described in many publications $[16,17]$.

\subsection{Scanning Electron Microscopy (SEM)}

Microstructural analysis was carried out using a JEOL JXA-8530F Hyperprobe (Electron Microprobe). Small rectangular pieces ( $10 \times 10 \mathrm{~mm}$ in size) were used for microscopic observations. The samples were from the interior portions of the beams, and it was shown in a companion study that the $\mathrm{CO}_{2}$ curing regimen adopted in this study resulted in carbonation across the entire depth for samples of comparable or larger sizes [12]. Prior to mounting, the sample was ultrasonically cleaned and rinsed with ethyl alcohol and dried with compressed air spray to remove debris from sectioning/handling. After drying, the sample was placed into a $32 \mathrm{~mm}$ two-part mounting cup, filled with a room-temperature setting epoxy, and subjected to $95 \mathrm{kPa}$ of vacuum for 5 minutes to remove entrapped air. After hardening, the sample was polished using 600 and 800 grit Silicon Carbide (SiC) abrasive discs, and further ground using $3 \mu \mathrm{m}$ and $1 \mu \mathrm{m}$ diamond paste. Final polishing was done with a $0.04 \mu \mathrm{m}$ colloidal silica suspension before they were placed under the electron gun of JEOL JXA-8530F Hyperprobe.

\subsection{Digital Image Correlation (DIC) for the Determination of Fracture Properties}

DIC is a non-contact optical method to analyze digital images to extract the full displacement field on a specimen surface $[15,18,19]$. Here, the beam surface was painted with random black and white speckles to improve image correlation. A charge coupled device (CCD) camera was used to record images every 5 seconds. After the collection of images during the entire loading-unloading sequence as described in the previous section, a suitable analysis region was chosen as shown in Figure 3(a) and image correlation performed to obtain the displacement fields on the specimen surface. 


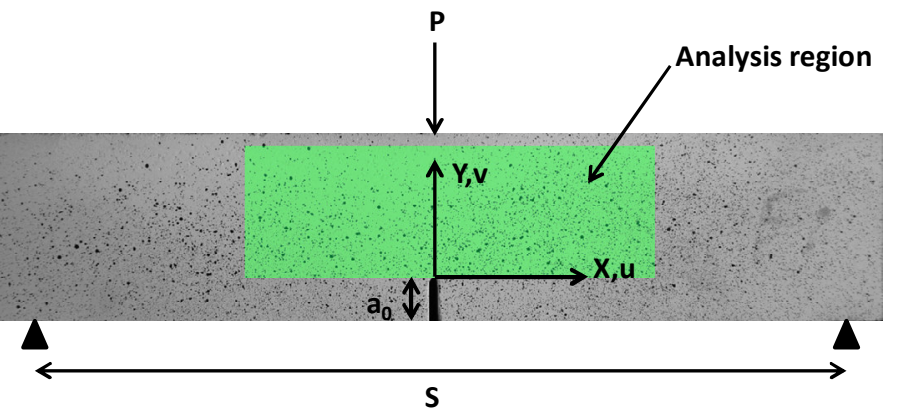

(a)

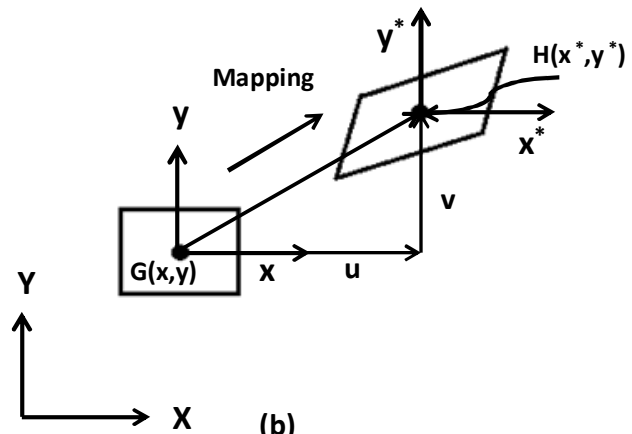

(b)

Figure 3: (a) Three-point bend specimen showing the analysis region for displacement field mapping, and (b) schematic of mapping of points in DIC

In the DIC method, the correlation between the subsets of images from the deformed and undeformed state is determined in order to calculate the displacement fields. A point $(x, y)$ in the undeformed state is mapped with a point $\left(x^{*}, y^{*}\right)$ in the deformed state as shown in Equation 1 and Figure 3(b).

$$
\begin{aligned}
& x^{*}=x+u(x, y) \\
& y^{*}=y+v(x, y)
\end{aligned}
$$

The horizontal ( $u$ ) and vertical $(v)$ displacement fields in the surface analysis region are then computed by minimization of the correlation coefficient (C) which can be defined as [20]:

$$
C=\frac{\sum\left[G(x, y)-H\left(x^{*}, y^{*}\right)\right]^{2}}{\sum G^{2}(x, y)}
$$

Here, $\mathrm{G}$ and $\mathrm{H}$ are grey scale light intensities corresponding to the point in the subset.

\subsection{RESULTS AND DISCUSSIONS}

\subsection{Microstructure of Iron Carbonate Binders}

As discussed earlier, microstructural analysis was carried out on polished iron carbonate binder samples to understand the material morphology and the impact of the material microstructure on its properties. The images shown here are for specimens cured for 6 days in a $\mathrm{CO}_{2}$ environment. Figure 4(a) shows the general appearance of the material microstructure with bright (high density) iron particles along with the reaction products and pores. The unreacted iron particles are, in general, elongated. The implications of these unreacted particles are discussed in the forthcoming section on fracture properties. The dense reaction products (the grey phases in the microstructure) are formed from the 
carbonation of smaller iron particles and their complexation with the other minor ingredients in the mixture, which was confirmed from a thermal analysis study to be belonging to the carbonate-oxalatecancrinite group [12]. A higher magnification image is shown in Figure 4(b) where an elongated iron particle and the surrounding microstructure containing spherical fly ash particles are shown. The dark regions in this microstructure are the pores, the volume fraction of which was found to be comparable to those of OPC-based systems as detailed in an extensive quantification work [12]. Dissolution of iron into the matrix from the particle and the formation of reaction products is shown in Figure 4(c).

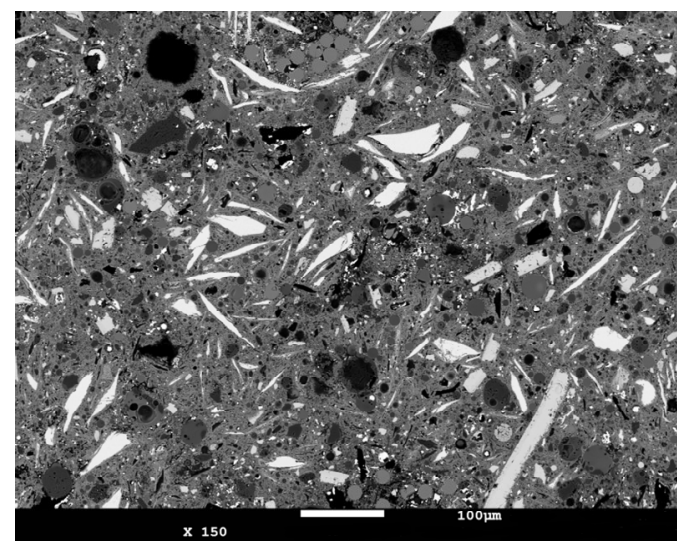

(a)

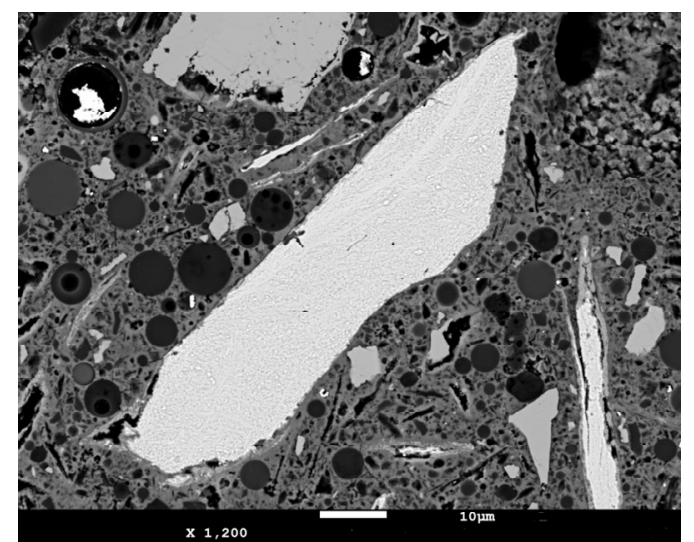

(b)

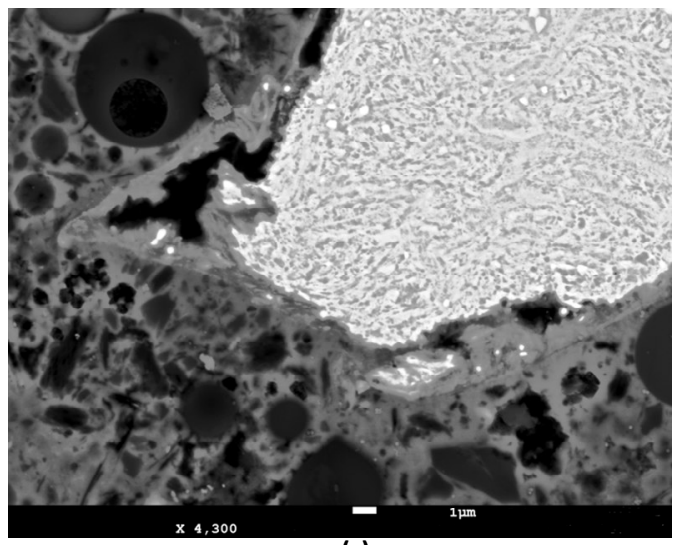

(c)
Figure 4: Microstructure of iron-based binder: (a) lower magnification (150X) image (scale bar corresponds to $100 \mu \mathrm{m}$ ); (b) higher magnification (1200X) image showing an elongated iron particle and the surrounding regions (scale bar corresponds to $10 \mu \mathrm{m}$ ); and (c) showing dissolution of $\mathrm{Fe}^{+2}$ from iron particle into the surrounding matrix (4300X) (Scale bar corresponds to $1 \mu \mathrm{m}$ ) 


\subsection{Flexural Strength}

201 The compressive strengths and the reaction product quantification in iron carbonate binder systems 202 have already been reported in detail [12,21]. Here, the flexural strengths of plain and fiber-reinforced 203 iron-based binder systems are reported along with their comparison to OPC systems. Figure 5 shows 204 the flexural strengths of plain and fiber-reinforced iron carbonate binders after 6 days of carbonation 205 and the corresponding OPC pastes after 28-days of hydration for comparison. The results presented 206 here suggest that the iron carbonate binder is about four-to-six times stronger than the traditional OPC 207 paste in flexure. This can be attributed to a combination of the stronger carbonate matrix along with the presence of unreacted iron particles in the microstructure as shown in Figure 4 . Both the binders are observed to exhibit increases in flexural strength with inclusion of fibers, with the iron-based system showing a much pronounced increase. While it has been proved that addition of glass fiber in OPC system results in increase in toughness with only minor increase in flexural strength [22-24], the ironbased binder shows a different trend where the flexural strength is increased significantly with the incorporation of glass fibers into the matrix. An enhancement in flexural strength of about $50 \%$ is observed for the iron-based binder when $0.5 \%$ glass fibers by volume is incorporated, but further fiber addition does not appear to correspondingly enhance the material behavior. Such an observation is

217 in a later section.

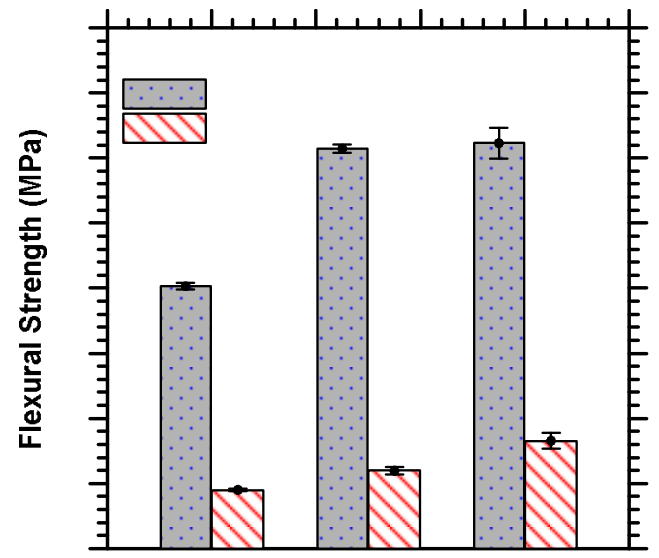

Figure 5: Comparison of flexural strength of 6-day carbonated iron Carbonate sample and OPC paste strength obtained from four replicate specimens) 


\subsection{Fracture of Notched Beams and Fracture Parameters}

224 In this paper, the fracture parameters of the iron-based and OPC binder systems are studied using the 225 TPFM. TPFM idealizes the pre-peak non-linear behavior in a notched specimen through an effective 226 elastic crack approach. The beam sizes and the notch depth are same for both the systems, thereby 227 rendering the comparisons of the fracture parameters free of size effects. The effect of fiber volume 228 fractions on the fracture parameters are also evaluated in conjunction with the response of the matrix 229 phase.

\subsubsection{Cyclic Load-CMOD response of notched beams}

231 The representative load-CMOD responses are shown in Figure 6 for the iron-based binder and the 232 companion OPC-based binder with and without fiber reinforcement. Figure 6(a) plots the load-CMOD 233 response for the control OPC and iron-based binder (without fiber reinforcement), which clearly depicts 234 the fundamental differences in the flexural response of these matrices. The significantly higher peak 235 load and improved post peak response of the iron-based binder as compared to control OPC binder can 236 be attributed to the presence of unreacted metallic iron particles (Figure 4) which are inherently strong 237 and ductile. It needs to be noted that the iron-based binder contains higher amounts of larger pores 238 (average size $>0.2 \mu \mathrm{m}$ ) even though the total pore volumes are comparable [21], and consequently, 239 demonstrates compressive strength that is slightly lower than that of the OPC binder [12]. However, the 240 presence of strong and ductile phases in the microstructure dominates the flexural response, as shown earlier. The incorporation of fibers in an OPC matrix makes it ductile as observed from the post-peak response and the larger CMODs for the fiber reinforced systems as opposed to the unreinforced materials shown in Figures 6(b) and (c); a response that is well documented. Both the peak load and the residual load are significantly higher for the iron carbonate binder, with and without fiber

245 reinforcement, depicted in Figures 7(a) and (b). The incorporation of glass fibers enhances the peak load of the iron-based binder much more than it does to the OPC binder, signifying the synergistic impact of

247 the iron carbonate matrix (including the unreacted iron particles) and fiber on the flexural response. The residual load for the control binders were measured at a CMOD value of $0.12 \mathrm{~mm}$ whereas a CMOD value of $0.25 \mathrm{~mm}$ was chosen for the binders with fiber reinforcement. The residual loads provide an indication of the crack-tolerance and the post-peak response of these systems. 

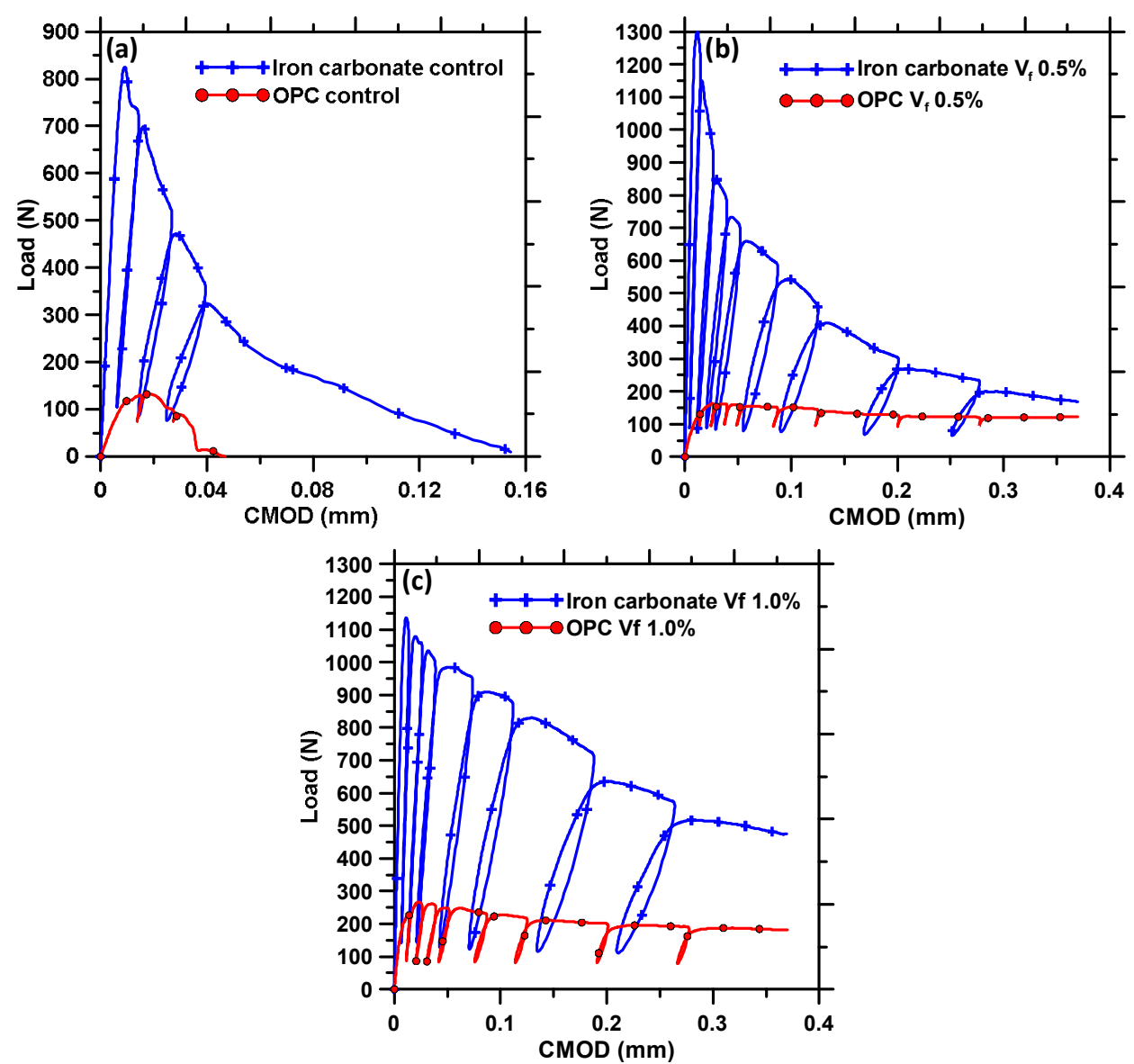

252 Figure 6: Representative Load-CMOD responses for iron carbonate binder and comparison with OPC 253 paste for (a) Control; (b) $0.5 \%$ and (c) $1.0 \%$ fiber volume fraction. Note that the $\mathrm{Y}$-axes scale for (a) are 254 different from those of (b) and (c) in order to ensure that the plain OPC mixture is shown at a reasonable size. 


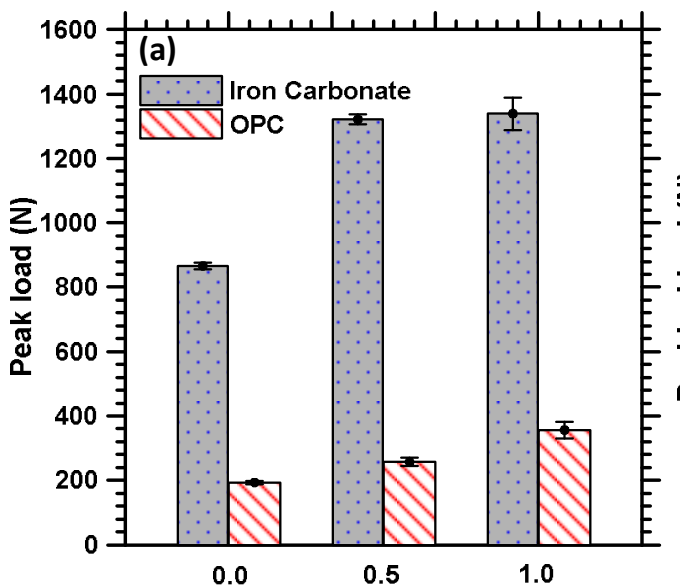

Fiber volume fraction $(\%)$

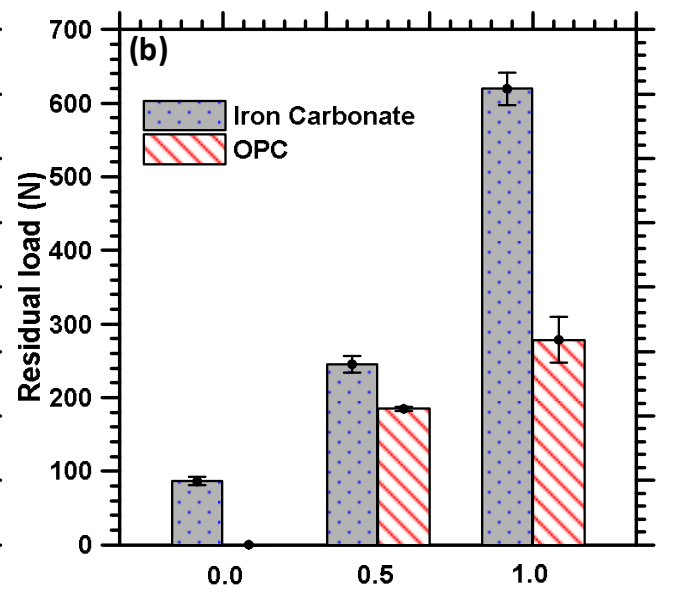

Fiber volume fraction $(\%)$

Figure 7: (a) Peak load, and (b) residual load of OPC and iron carbonate binders as a function of fiber volume fraction. (The error bars represent one standard deviation of peak and residual loads obtained from three replicate specimens)

\subsection{2 $\mathrm{K}_{\mathrm{IC}}{ }^{\mathrm{S}}$ and $\mathrm{CTOD}_{\mathrm{c}}$ of iron carbonate composite systems and their comparison to OPC-based systems}

Figure 8 reports the two major fracture parameters-fracture toughness $\left(\mathrm{K}_{\mathrm{IC}}{ }^{\mathrm{S}}\right)$ and critical crack tip opening displacement $\left(\mathrm{CTOD}_{\mathrm{C}}\right)$ derived using TPFM for both the binders, as a function of the fiber volume fraction. Figure $8(a)$ shows that the fracture toughness values of the iron-based binders are much higher than those of the control OPC binders ( 5-7 times) irrespective of the fiber volume fraction. An increase in fiber volume fraction is found to enhance the toughness of both the binder systems, as expected, attributed to the crack-bridging effects of the fiber and the resultant increase in energy dissipation under load. The $\mathrm{K}_{\mathrm{IC}}{ }^{\mathrm{S}}$ values of the iron carbonate binder range from $30 \mathrm{MPa} \cdot \mathrm{mm}^{0.5}$ to $50 \mathrm{MPa} . \mathrm{mm}^{0.5}$, which is approximately half of those of glass ceramics [25], polycrystalline cubic zirconia, SiN, Alumina [26] and high-performance structural ceramics such as SiC [27], and five times larger than the companion OPC binder. It is noteworthy to state that the above-mentioned ceramics are prepared via high-temperature processing whereas the iron-based binder in this study is processed at ambient temperature and pressure in a $\mathrm{CO}_{2}$ environment. In the unreinforced OPC matrix, the only mechanism of strain energy dissipation is crack extension. The significantly higher $\mathrm{K}_{\mathrm{IC}}{ }^{\mathrm{S}}$ of the iron-based binder, even for the unreinforced case, as compared to the OPC binder could be attributed to the crack bridging and/or deflection effects of the ductile, unreacted metallic iron particles in the matrix, many of them which are elongated as can be observed from the micrographs in Figure 4. The strong reinforcing phase (the unreacted metallic particles) imposes a closing pressure on the crack thereby bridging the cracks and the elastic incompatibility and debonding between the metallic particle-carbonate matrix interfaces contributes to crack deflection. The influence of the unreacted iron particles in improving the crack 
resistance and toughness is augmented by the toughening mechanisms due to the incorporation of fibers, as can be noticed from Figure 8(a). Beyond a certain volume fraction of fibers, further toughness enhancement is negligible for the iron-based binders because the distribution of the unreacted iron particles and the fibers in the matrix is expected to be sufficient for crack bridging/deflection. However, as expected, an increase in fiber volume fraction, in the ranges reported in this paper, enhances the toughness of the OPC-based binder system, the reasons for which are well documented [28-33].
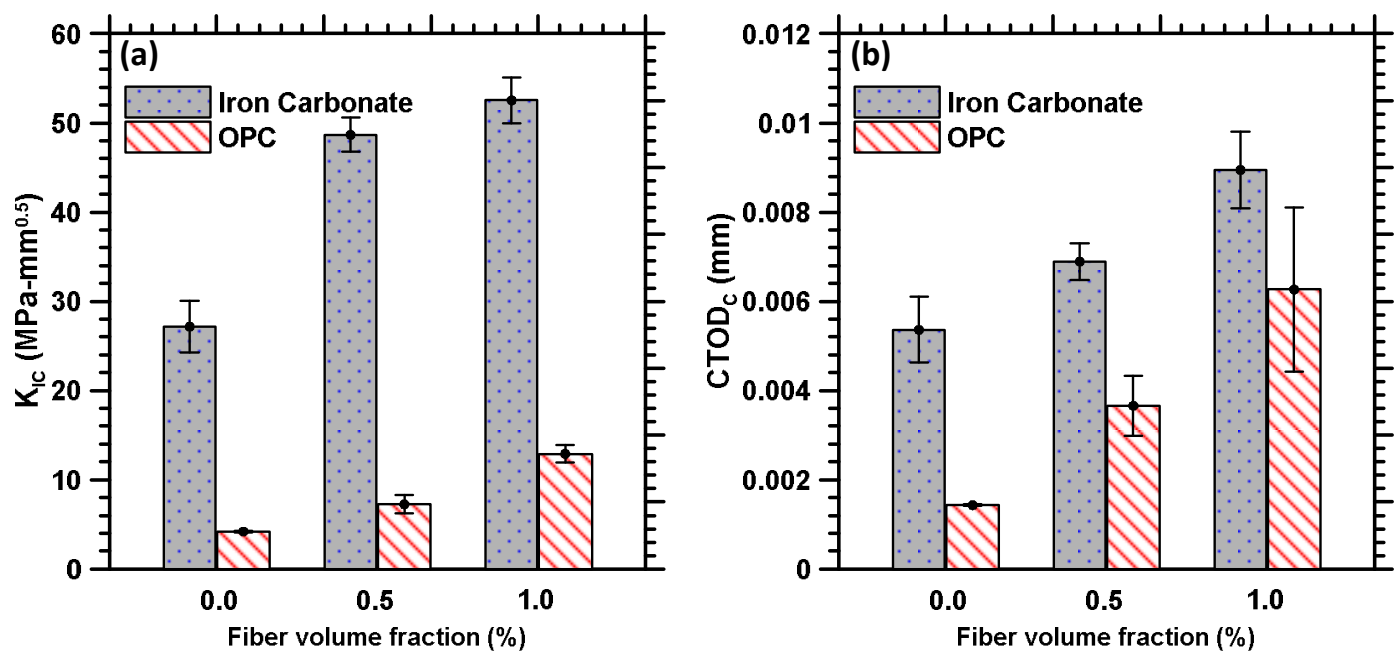

Figure 8: (a) Fracture toughness, and (b) critical crack tip opening displacements of iron carbonate and OPC-based binders. (The error bars represent one standard deviation of $\mathrm{K}_{\mathrm{IC}}$ and $\mathrm{CTOD}_{\mathrm{C}}$ obtained from

The critical crack tip opening displacements $\left(C T O D_{c}\right)$, which indicates the limit beyond which unstable crack propagation begins is shown in Figure $8(\mathrm{~b})$ as a function of the fiber volume fraction for both the binders. A rather consistent increase in $\mathrm{CTOD}_{\mathrm{c}}$ with fiber volume fraction is observed for both the binders. The unstable crack propagation threshold limit $\left(\mathrm{CTOD}_{\mathrm{C}}\right)$ for the unreinforced iron-based control binder is found to be about three times higher as compared to that of the corresponding OPC paste, also attributable to the reasons described earlier. The difference in $\mathrm{CTOD}_{\mathrm{c}}$ between the two binder types reduce to a certain extent as fibers are incorporated. The $K_{I C}$ and $C_{T O D}$ values of the two binders indicate that the iron-based binder yields significantly improved crack resistance and ductility than the conventional OPC systems due to the presence of unreacted metallic iron powder surrounded by a carbonate matrix $[12,21]$.

The $\mathrm{K}_{\mathrm{IC}}-\mathrm{CTOD}_{\mathrm{C}}$ relationships of the two binders are compared in Figure 9(a), where an increase in the 304 fracture toughness is observed with an increase in the critical opening size of the crack. While the increase in $\mathrm{K}_{\mathrm{IC}}{ }^{\mathrm{S}}$ is proportional to an increase in $\mathrm{CTOD}_{\mathrm{c}}$ for the OPC binders, for the iron-based binder, 
306

307

308

309

310

311

312

313

314

315

316

317

the increase in $\mathrm{K}_{\mathrm{IC}}{ }^{\mathrm{S}}$ is not prominent beyond a certain $\mathrm{CTOD}_{\mathrm{c}}$ value (or fiber volume fraction, since $\mathrm{CTOD}_{\mathrm{c}}$-fiber volume fraction relationships are linear for both the binder systems as shown in Figure $8(b))$. The reason for this observation was provided earlier. The critical crack length $\left(a_{c}\right)$ values obtained from TPFM are shown in Figure 9(b), as a function of the fiber volume fraction. The critical crack length increases with increase in fiber volume for both the binders as expected. In unreinforced binders, the iron-based system has a higher critical crack length owing to the contribution from elongated, elastic iron particles. However, at a higher fiber volume fraction, the critical crack lengths for both the binders are comparable even though $\mathrm{K}_{\mathrm{IC}}{ }^{\mathrm{S}}$ and $\mathrm{CTOD}_{\mathrm{c}}$ are higher for the iron-based binder. This shows that, in the iron-based systems, beyond a certain fiber volume fraction, enhancement in fracture properties are negligible for reasons explained earlier (even though the performance is much better than that of the corresponding OPC systems). This aspect is investigated in further detail through the use of resistance curves in the following section.
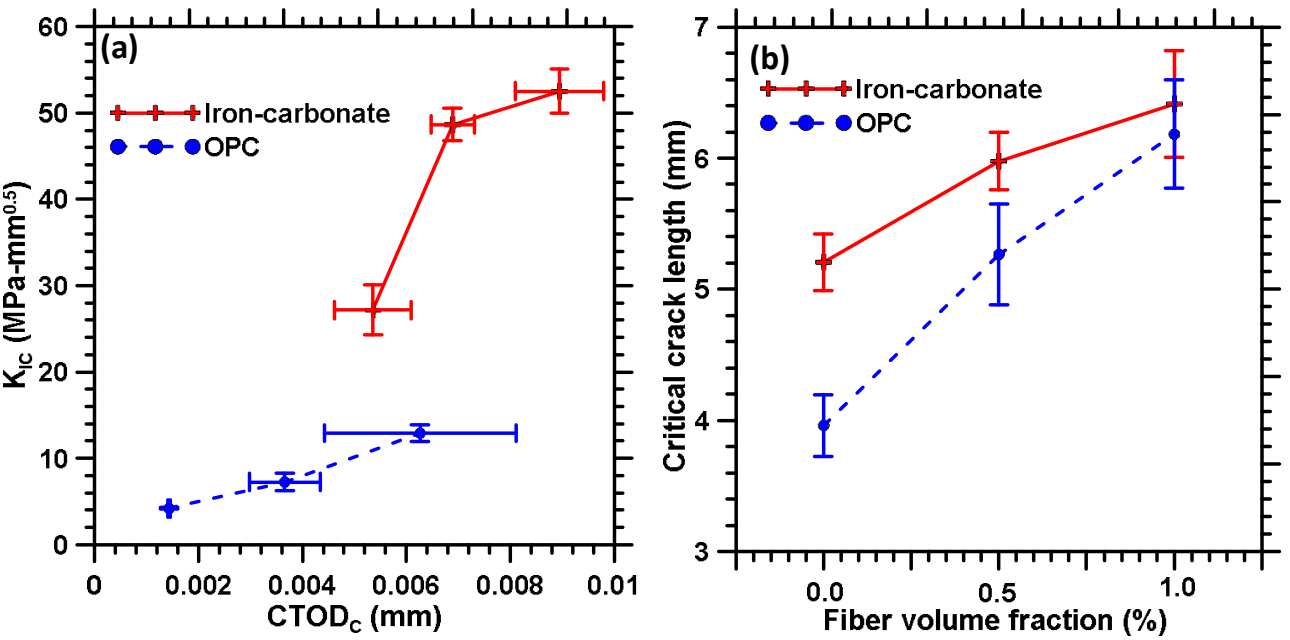

Figure 9: (a) Fracture toughness-critical crack tip opening displacement relationship; (b) Variation in critical crack length with change in fiber dosage for iron carbonate binder and OPC.

\subsubsection{Matrix and fiber effects on the strain energy release rates}

In order to explore the influence of matrix (including the unreacted, elongated iron particles) and the fibers on the fracture response, this section utilizes the resistance curves (R-curves) [15,34-39]. Rcurves are developed here by making use of the multiple loading-unloading cycles in the load-CMOD plots as shown in Figure 6. $\mathrm{R}$ is defined as the strain energy rate required for crack propagation and it is an increasing and convex function for quasi-brittle materials. The contribution from both the elastic and inelastic strain energies are considered in the development of the R-curve, which makes it beneficial in 
obtaining a better understanding of the matrix and fiber effects. The elastic component is calculated

329 from the unloading compliances whereas the inelastic CMOD is used to calculate the inelastic strain energy release rate. The total strain energy release rate $\left(G_{R}\right)$ is given as $[15,34,35,37-39]$ :

$$
G_{R}=G_{\text {elastic }}+G_{\text {inelastic }}=\frac{P^{2}}{2 t} \frac{\partial C}{\partial a}+\frac{P}{2 t} \frac{\partial\left(C M O D_{\text {inelastic }}\right)}{\partial a}
$$

332 Here $\mathrm{C}$ is the unloading compliance, $\mathrm{t}$ is the thickness of the specimen, $\mathrm{P}$ is the applied load, and $\mathrm{a}$ is the 333 crack length.

334 A compliance-based approach $[15,34,35]$ is used in this study to develop the resistance curves. This 335 approach is based on the assumption that stable crack propagation leads to an increase in compliance. 336 Three parameters were obtained for each loading-unloading cycle (Figure 6): the compliance, the load at 337 the initiation of the unloading, and inelastic CMOD, which is the residual displacement when the sample 338 is unloaded. The unloading compliance is used to solve for the effective crack length $\left(a_{0}+\Delta a\right.$, where $\Delta a$ 339 is the crack extension) using a non-linear equation described in $[15,34]$. The compliance and the inelastic 340 CMOD are then plotted as functions of the crack length and the relationships differentiated to obtain 341 the rate terms in Equation 3.

342 Figure 10 shows the R-curves for both the binder systems at all levels of fiber reinforcements. The R343 curves comprise of a region where the resistance increases with crack length denoting the formation of 344 a process zone and an energy plateau denoting steady-state crack extension. The location of the 345 transition point between the two regions depends on the matrix type and fiber volume as can be 346 observed from Figure 10. The unreinforced OPC system shows almost negligible resistance whereas the 347 corresponding iron-based system demonstrates some resistance to crack formation and growth, 348 attributable to the reasons described elsewhere in this paper. The use of fiber reinforcement improves 349 the crack growth resistance of OPC systems, but the overall resistances are significantly lower than 350 those of the iron-based binder systems. 


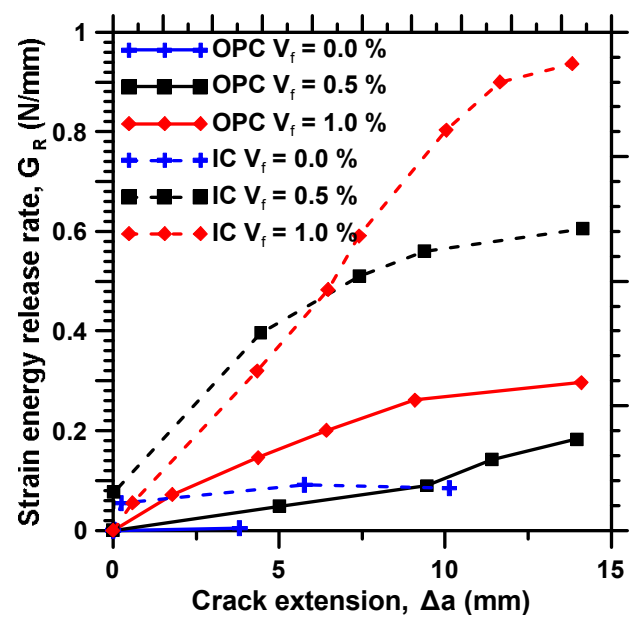

Figure 10: Resistance curves for the unreinforced and fiber reinforced iron-based and OPC binder systems

354 It is instructive to separate the elastic and inelastic components of the strain energy release rate to obtain further insights on the relative influence of matrix (and the discrete phases in it) and the fiber reinforcement on the fracture response of these widely different material systems. The results are presented in Figures 11(a) and (b) for the iron- and OPC-based binder systems respectively. The elastic component of the strain energy release rate corresponds to the energy release rate due to incremental crack growth whereas the inelastic component corresponds to effects such as permanent deformation caused due to crack-opening. An important observation from these figures is that the contribution of the elastic component to the overall strain energy release rate is found to be higher than the inelastic component for the iron-based binder systems (both unreinforced and reinforced) whereas for the OPC systems, the contribution of inelastic component is higher. It is also found that both the elastic and the inelastic components increase with increase in crack extension for the fiber-reinforced iron-based system whereas for the fiber-reinforced OPC systems, the elastic component remains relatively constant with crack extension and the increase in total strain energy is mainly due to increase in the

367 inelastic component. The higher contribution of the elastic component in the iron-based systems is 368 attributed to the presence of a stronger matrix along with the presence of elastic metallic iron particles that provide crack growth resistance through the mechanisms described earlier. On the contrary, the 370 brittle OPC matrix cracks easily, and consequently the load is carried almost completely by the fibers. 371 The fibers bridge the crack and energy dissipation is obtained through crack opening, which is reflected 372 in the form of increased inelastic strain energy with increasing crack extension. The R-curve response is 373 consistent with the values of fracture parameters $\left(\mathrm{K}_{\mathrm{IC}}{ }^{\mathrm{S}}\right.$ and $\left.\mathrm{CTOD}_{\mathrm{C}}\right)$ of these binders. The fracture 374 toughness of the iron-based systems was found to be much higher than that of the OPC systems 
whereas the $\mathrm{CTOD}_{\mathrm{c}}$ values of the two binders demonstrated reduced degrees of difference. The same trends are reflected in the R-curves: about an order of magnitude higher crack growth resistance (elastic contribution) observed for the iron-based systems than that of the OPC systems and comparatively lesser improvement (about 60\% higher) in the crack-opening resistance (inelastic contribution).
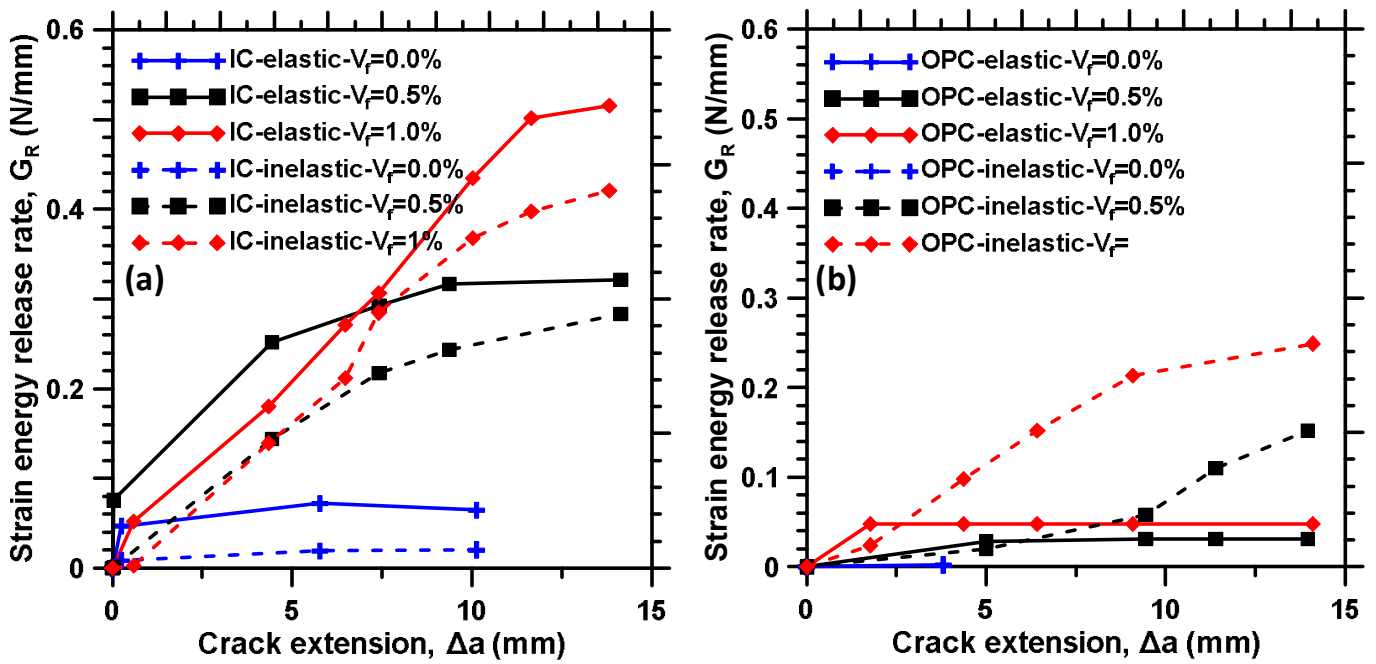

Figure 11: Elastic and inelastic components of crack growth resistance with varying crack extension for (a) iron Carbonate binder and (b) OPC paste for different fiber dosage

\subsection{Use of Digital Image Correlation (DIC) to Determine $\mathrm{K}_{\mathrm{IC}}$ and $\mathrm{CTOD}_{\mathrm{c}}$}

DIC is a very useful non-contact optical method to measure displacement fields [40-44]. DIC has been employed in several studies, including those of the authors, to evaluate fracture responses of several materials $[15,18,20,45,46]$. To demonstrate the effectiveness of this method for the novel iron-based binder systems, two representative iron carbonate binders ( $0 \%$ and $1 \%$ fiber volume fraction) are used here for the extraction of fracture parameters through DIC. Figure 12(a) shows the load-CMOD response for the fiber-reinforced iron-based binder, where the points P1-to-P3 correspond to three different stages of crack extension, i.e., in the pre-peak, near-peak, and post-peak stages. The compliance value obtained by unloading at approximately $95 \%$ of the peak load in the post-peak region is used for the determination of $\mathrm{K}_{\mathrm{IC}}{ }^{\mathrm{S}}$ and $\mathrm{CTOD}_{\mathrm{C}}$ using TPFM, which is required in order to compare with the corresponding values obtained using the DIC technique. The horizontal u-displacement fields (along the crack opening direction) are obtained from image correlation by employing VIC-2D software ${ }^{\mathrm{TM}}$ (commercially available, developed by Correlated Solutions). Figure 12(b) shows the plot of the crack opening, denoted by the horizontal displacement, and the crack extension, denoted by the jump in the displacement above the notch, which can be extracted from the DIC data [15]. As can be observed here, 
the CTOD and $\triangle a$ values can be determined directly using the DIC method without instrumenting the crack for precise measurements. A threshold value of $0.005 \mathrm{~mm}$ is set to qualify the displacement-jump as contributing to crack extension. The crack extension corresponding to $95 \%$ of the peak load in the post-peak region is used to determine the DIC-based fracture toughness parameters using a set of simplified expressions as shown later.

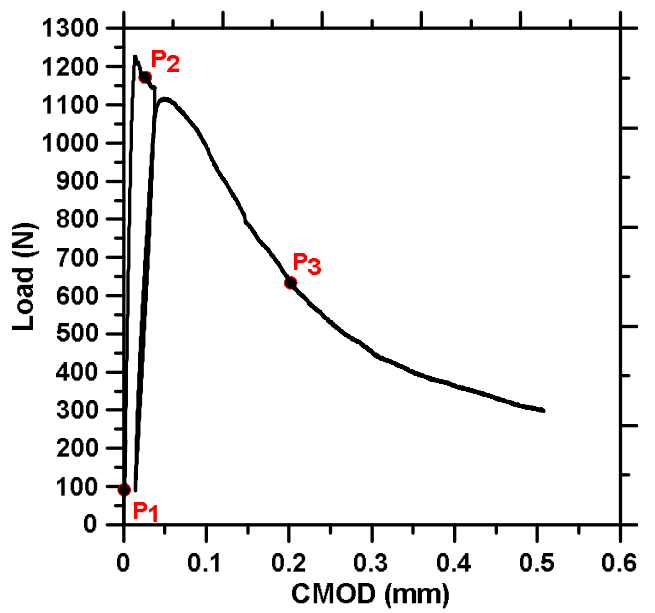

(a)

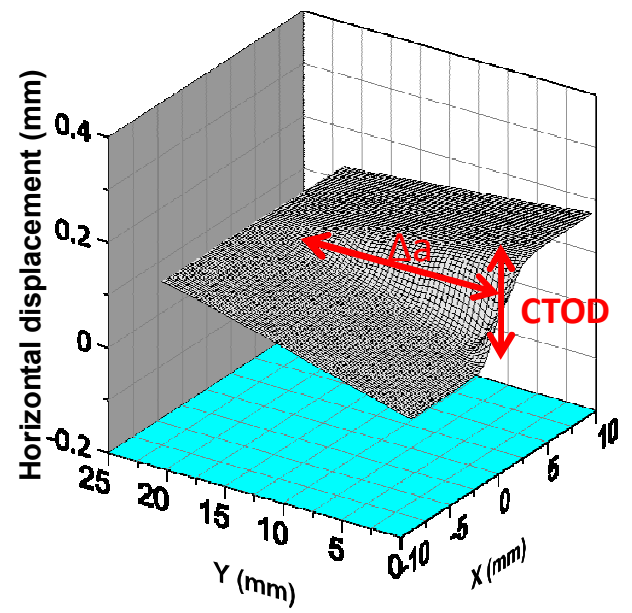

(b)

Figure 12: (a) Load-CMOD response for iron carbonate binder with $1 \%$ fiber volume fraction, and (b) horizontal (u) displacement field represented as a 3D surface plot

The 2D displacement fields for the iron-based binder are shown in Figure 13 for three different CTOD values which were selected as shown in Figure 12(a). Figures 13 (a), (c) and (e) show the 2D crack opening displacements, corresponding to the points P1, P2 and P3 of Figure 12(a) whereas Figures 13 (b), (d) and (f) shows the corresponding horizontal displacements as 3D surface plots. Figure 13(a) corresponds to the case where only a very small load is applied to the specimen (Point P1 in Figure 12(a)), and the values of both CTOD and crack extension are zero, as shown by the uniform horizontal displacement fields above the notch as well as a flat surface plot (Figure 13(b)). Figure 13(c) corresponds to $95 \%$ of the peak load in the post-peak zone (Point P2 in Figure 12(a)). A displacement jump is clearly visible above the notch in both the 2D displacement field (Figure 13(c)) and the 3D surface plots (Figure 13(d)). Beyond this point, the crack extension is found to be unstable (a large increase in CTOD and crack extension). Figures 13 (e) shows the displacement field corresponding to Point P3 in Figure 12(a). The CTOD and $\Delta$ a values are very high in the post-peak zone. 


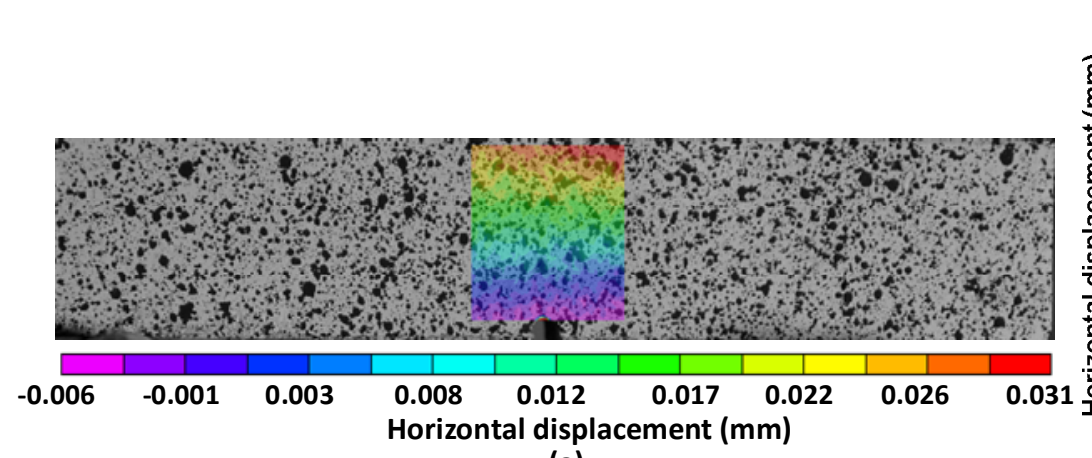

(a)
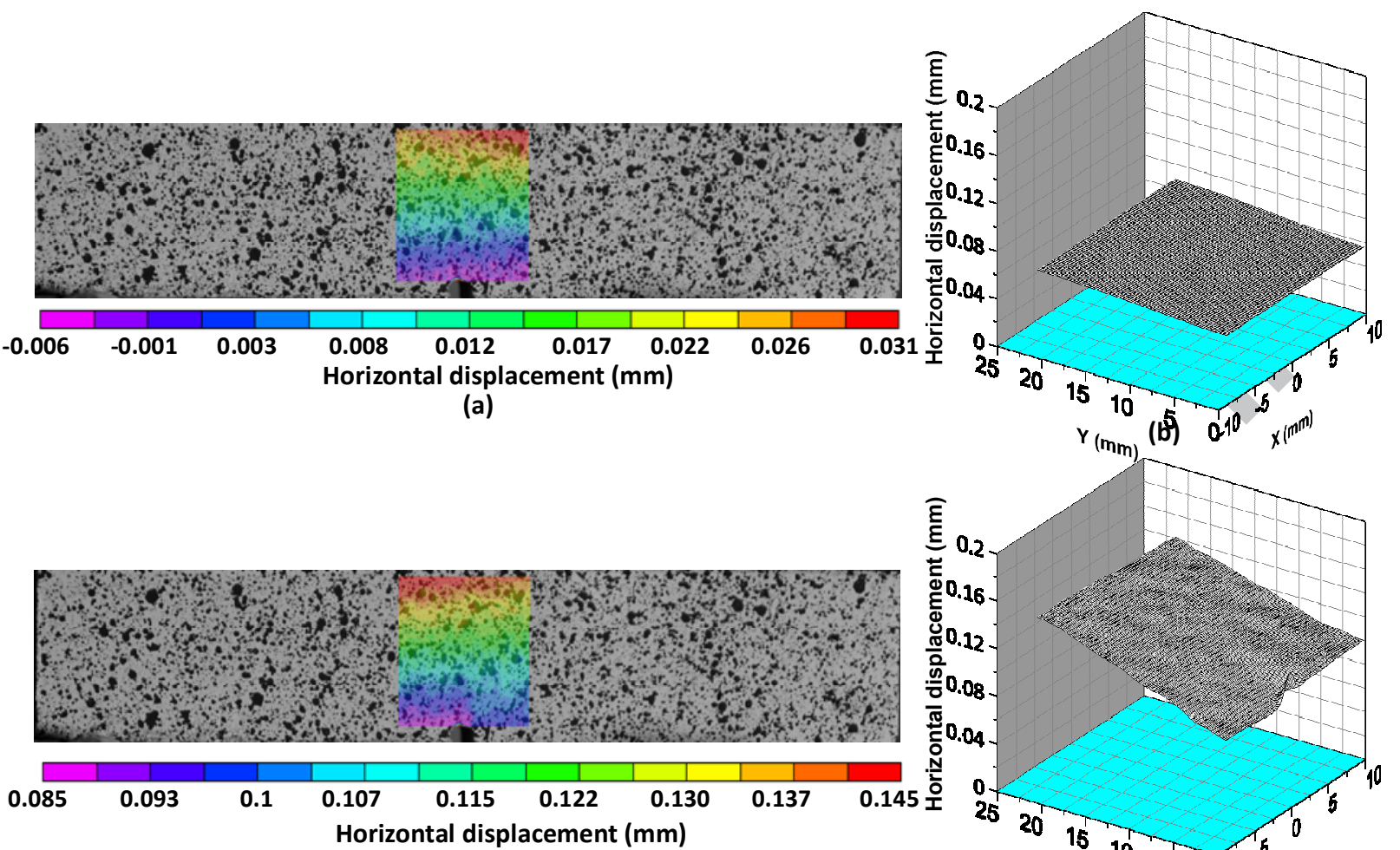

(c)
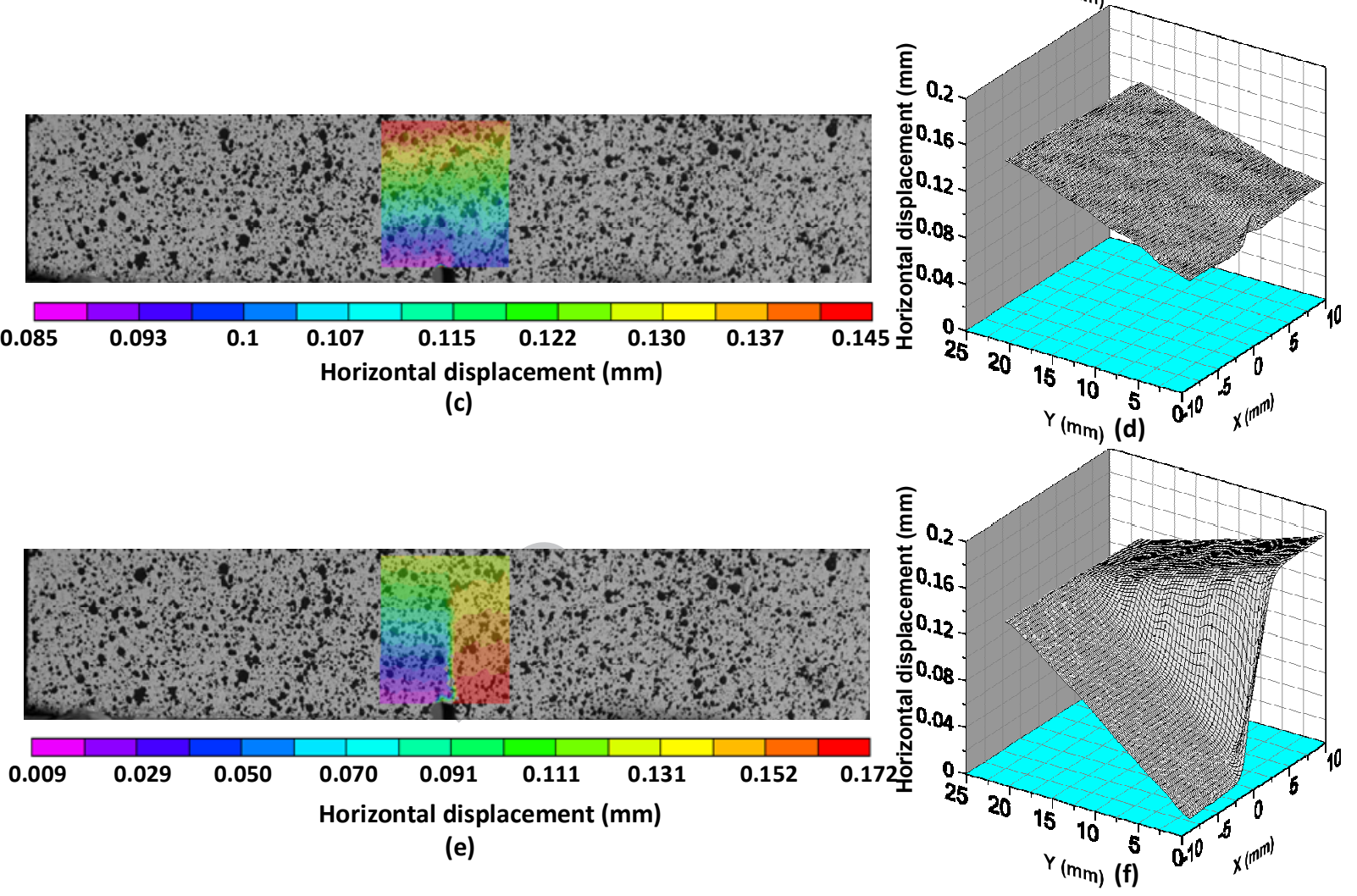

Figure 13: Horizontal displacement fields and the 3D surface plots for unreinforced and reinforced (1\% fiber volume fraction) iron-based binders corresponding to: (a) and (b) pre-crack stage: P1 (CMOD: $0.0009 \mathrm{~mm}$, Load: $91.4 \mathrm{~N}, \Delta a=0 \mathrm{~mm}, \mathrm{CTOD}=0 \mathrm{~mm}$ ); (c) and (d) stable crack growth stage: P2 (CMOD:

424 To determine $\mathrm{K}_{\mathrm{IC}}$ and $\mathrm{CTOD}_{\mathrm{C}}$ from the DIC data, values at $95 \%$ of the peak load in the post-peak zone are

425 considered. $K_{\mathrm{IC}}$ for a notched beam in three-point bending can be determined as $[18,47,48]$ as:

$$
K_{I C}=\frac{P L}{b d^{3 / 2}} F\left[\frac{a_{e f f}}{d}\right]
$$


The geometry function $F\left(a_{\text {eff }} / d\right)$ is given as:

$F\left[\frac{a_{\text {eff }}}{d}\right]=\left[2.9\left(\frac{a_{\text {eff }}}{d}\right)^{1 / 2}-4.6\left(\frac{a_{\text {eff }}}{d}\right)^{3 / 2}+21.8\left(\frac{a_{\text {eff }}}{d}\right)^{5 / 2}-37.6\left(\frac{a_{\text {eff }}}{d}\right)^{7 / 2}+38.7\left(\frac{a_{\text {eff }}}{d}\right)^{9 / 2}\right]$

where the effective crack length, $a_{\text {eff }}=a_{0}+\Delta a$.

The $\mathrm{CTOD}_{\mathrm{C}}$ and $\mathrm{K}_{\mathrm{IC}}$ values are also calculated using the TPFM for comparison and are reported in Table 1. For the iron-based binders, there is a good correlation between the $\mathrm{K}_{\mathrm{IC}}$ and $\mathrm{CTOD}_{\mathrm{c}}$ values obtained from the contact and non-contact methods, establishing the use of DIC-based techniques as a viable means for non-contact sensing of structural damage parameters.

Table 1: Comparison of the $\mathrm{K}_{\mathrm{IC}}$ and $\mathrm{CTOD}_{\mathrm{c}}$ values determined using TPFM and DIC

\begin{tabular}{|c|c|c|c|c|}
\hline \multirow{2}{*}{ Specimen composition } & \multicolumn{2}{|c|}{$\mathrm{K}_{\mathrm{IC}}\left(\mathrm{MPa} \cdot \mathrm{mm}^{0.5}\right)$} & \multicolumn{2}{c|}{$\mathrm{CTOD}_{\mathrm{c}}(\mathrm{mm})$} \\
\cline { 2 - 5 } & $\mathrm{TPFM}$ & $\mathrm{DIC}$ & $\mathrm{TPFM}$ & $\mathrm{DIC}$ \\
\hline Iron carbonate $($ Control) & 31.40 & 33.56 & 0.0062 & 0.0040 \\
\hline Iron carbonate $\left(\mathrm{V}_{\mathrm{f}}=1.0 \%\right)$ & 52.53 & 54.14 & 0.0089 & 0.0096 \\
\hline
\end{tabular}

\subsection{CONCLUSIONS}

This paper has evaluated the flexural fracture response of a novel iron-based binder and compared it with the performance of OPC-based matrices which are the most common and cheapest of the available ceramic matrices. The iron-based binder was prepared by the aqueous carbonation of metallic iron powder (which contained particles of large aspect ratios also) along with other chosen minor ingredients. Microstructural studies showed a dense reaction product intermixed with pores and unreacted, elongated iron particles. The flexural strength, fracture toughness $\left(\mathrm{K}_{\mathrm{IC}}{ }^{\mathrm{S}}\right)$, and the critical crack tip opening displacement $\left(C T O D_{c}\right)$ of the iron-based binders were significantly higher than those of the OPC matrices, for both the unreinforced and glass-fiber reinforced systems. The improved performance of the iron-based binder systems were attributed to the presence of the elastic, unreacted metallic particles that facilitate crack bridging and deflection. The use of glass fibers was found to enhance the toughness of OPC-based systems as is well known. For the iron-based binders, up to a certain fiber volume fraction, toughness enhancement was observed. The benefits were negligible beyond that because a further increase in fiber volume was not required to ensure crack bridging/deflection in the presence of elongated iron particles. The $\mathrm{K}_{\mathrm{IC}}{ }^{\mathrm{S}}$ and $\mathrm{CTOD}_{\mathrm{c}}$ values for the iron-based binders were also obtained through a non-contact digital image correlation method, which provided comparable fracture parameters as those determined from the TPFM. 
R-curves, developed using a compliance-based approach, were used to explore the relative influence of the matrix and the fibers on the fracture response of the novel binder systems. The iron-based binder systems showed significantly higher strain energy release rates than the OPC-based binder at all fiber loadings. The elastic (corresponding to the energy release rate due to incremental crack growth) and inelastic (permanent deformation caused due to crack-opening) components of the strain energy release rate were separated. It was found that the elastic component of the strain energy release rate was higher than the inelastic component for iron-based binders, attributable to the superior effects of the unreacted metallic particulate phase that provide crack growth resistance. For the fiber reinforced OPC system, the energy dissipation is obtained through crack opening only, which resulted in an increased contribution of the inelastic component towards the total strain energy release. The results

463 from this study has established the improved flexural and fracture performance of a novel and sustainable composite material.

\subsection{ACKNOWLEDGEMENTS}

The authors sincerely acknowledge the support from National Science Foundation (CMMI: 1353170) towards the conduct of this study. The contents of this paper reflect the views of the authors who are responsible for the facts and accuracy of the data presented herein, and do not necessarily reflect the views and policies of NSF, nor do the contents constitute a standard, specification or a regulation. We gratefully acknowledge the use of facilities within the Laboratory for the Science of Sustainable Infrastructural Materials (LS-SIM) and the LeRoy Eyring Center for Solid State Sciences (LE-CSSS) at Arizona State University. Raw materials were provided by Schuff Steel, Iron Shell LLC, Omya AG, Headwaters Inc., and Burgess Pigments, which are acknowledged.

\subsection{REFERENCES}

475

476

477

478

479

480

481

482

483

484

485

486

[1] Chen C, Habert G, Bouzidi Y, Jullien A. Environmental impact of cement production: detail of the different processes and cement plant variability evaluation. J Clean Prod 2010;18:478-85.

[2] Peters GP, Andrew RM, Boden T, Canadell JG, Ciais P, Le Quéré $C$, et al. The challenge to keep global warming below $2{ }^{\circ} \mathrm{C}$. Nat Clim Change 2013;3:4-6.

[3] Cagiao J, Gómez B, Doménech JL, Mainar SG, Lanza HG. Calculation of the corporate carbon footprint of the cement industry by the application of MC3 methodology. Ecol Indic 2011;11:152640.

[4] Barcelo L, Kline J, Walenta G, Gartner E. Cement and carbon emissions. Mater Struct 2014;47:1055-65.

[5] Zhang J, Cheng JCP, Lo IMC. Life cycle carbon footprint measurement of Portland cement and ready mix concrete for a city with local scarcity of resources like Hong Kong. Int J Life Cycle Assess 2014;19:745-57. 
[6] Worrell E, Price L, Martin N, Hendriks C, Meida LO. Carbon Dioxide Emissions from the Global

[7] Lothenbach B, Scrivener K, Hooton RD. Supplementary cementitious materials. Cem Concr Res 2011;41:1244-56.

[8] Ramezanianpour AA, Bahrami Jovein $\mathrm{H}$. Influence of metakaolin as supplementary cementing material on strength and durability of concretes. Constr Build Mater 2012;30:470-9.

[9] Kumar A, Oey T, Falla GP, Henkensiefken R, Neithalath N, Sant G. A comparison of intergrinding and blending limestone on reaction and strength evolution in cementitious materials. Constr Build Mater 2013;43:428-35.

[10] Ravikumar D, Peethamparan S, Neithalath N. Structure and strength of $\mathrm{NaOH}$ activated concretes containing fly ash or GGBFS as the sole binder. Cem Concr Compos 2010;32:399-410.

[11] Vance K, Aguayo M, Oey T, Sant G, Neithalath N. Hydration and strength development in ternary portland cement blends containing limestone and fly ash or metakaolin. Cem Concr Compos 2013;39:93-103.

[12] Das S, Souliman B, Stone D, Neithalath N. Synthesis and Properties of a Novel Structural Binder Utilizing the Chemistry of Iron Carbonation. ACS Appl Mater Interfaces 2014;6:8295-304.

[13] Trusty PA, Yeomans JA. The toughening of alumina with iron: Effects of iron distribution on fracture toughness. J Eur Ceram Soc 1997;17:495-504.

[14] Kumar R, Thangaraj A, Bhat RN, Ratnasamy P. Synthesis of iron-silicate analogs of zeolite beta. Zeolites 1990;10:85-9.

[15] Das S, Aguayo M, Dey V, Kachala R, Mobasher B, Sant G, et al. The fracture response of blended formulations containing limestone powder: Evaluations using two-parameter fracture model and digital image correlation. Cem Concr Compos 2014;53:316-26.

[16] Jenq Y, Shah SP. Two parameter fracture model for concrete. J Eng Mech 1985;111:1227-41.

[17] Shah SP. Fracture mechanics of concrete: applications of fracture mechanics to concrete, rock and other quasi-brittle materials. John Wiley \& Sons; 1995.

[18] Nunes LCS, Reis JML. Estimation of crack-tip-opening displacement and crack extension of glass fiber reinforced polymer mortars using digital image correlation method. Mater Des 2012;33:24853.

[19] Roux S, Réthoré J, Hild F. Digital image correlation and fracture: an advanced technique for estimating stress intensity factors of 2D and 3D cracks. J Phys Appl Phys 2009;42:214004.

[20] Yates JR, Zanganeh M, Tai YH. Quantifying crack tip displacement fields with DIC. Eng Fract Mech 2010;77:2063-76.

[21] Das S, Stone DA, Convey D, Neithalath N. Pore- and Micro-structural Characterization of a Novel Structural Binder based on Iron Carbonation. Mater Charact 2014;98:168-179.

[22] Sivakumar A, Santhanam M. Mechanical properties of high strength concrete reinforced with metallic and non-metallic fibres. Cem Concr Compos 2007;29:603-8.

[23] Altun F, Haktanir T, Ari K. Effects of steel fiber addition on mechanical properties of concrete and RC beams. Constr Build Mater 2007;21:654-61.

[24] Kwan WH, Ramli M, Cheah CB. Flexural strength and impact resistance study of fibre reinforced concrete in simulated aggressive environment. Constr Build Mater 2014;63:62-71.

[25] HAN W. Glass ceramic of high hardness and fracture toughness developed from iron-rich wastes. Acta Metall Sin Engl Lett 2009;22:181-90.

[26] Becher PF. Microstructural Design of Toughened Ceramics. J Am Ceram Soc 1991;74:255-69.

[27] Mukhopadhyay AK, Datta SK, Chakraborty D. Fracture toughness of structural ceramics. Ceram Int 1999;25:447-54.

[28] Tassew ST, Lubell AS. Mechanical properties of glass fiber reinforced ceramic concrete. Constr Build Mater 2014;51:215-24. 
[29] Banthia N, Sheng J. Fracture toughness of micro-fiber reinforced cement composites. Cem Concr Compos 1996;18:251-69.

[30] Gopalaratnam VS, Gettu R. On the characterization of flexural toughness in fiber reinforced concretes. Cem Concr Compos 1995;17:239-54.

[31] Reis JML. Fracture and flexural characterization of natural fiber-reinforced polymer concrete. Constr Build Mater 2006;20:673-8.

[32] Bakhshi M, Barsby C, Mobasher B. Comparative evaluation of early age toughness parameters in fiber reinforced concrete. Mater Struct 2014;47:853-72.

[33] Banthia N, Majdzadeh F, Wu J, Bindiganavile V. Fiber synergy in Hybrid Fiber Reinforced Concrete (HyFRC) in flexure and direct shear. Cem Concr Compos 2014;48:91-7.

[34] Mobasher B. Mechanics of fiber and textile reinforced cement composites. CRC Press; 2011.

[35] Wecharatana M, Shah SP. A model for predicting fracture resistance of fiber reinforced concrete. Cem Concr Res 1983;13:819-29.

[36] Chengsheng O, Barzin M, Surendra P. S. An r-curve approach for fracture of quasi-brittle materials. Eng Fract Mech 1990;37:901-13.

[37] Mai YW, Hakeem MI. Slow crack growth in cellulose fibre cements. J Mater Sci 1984;19:501-8.

[38] Sakai M, Bradt RC. Graphical methods for determining the nonlinear fracture parameters of silica and graphite refractory composites. Fract. Mech. Ceram., Springer; 1986, p. 127-42.

[39] Arino AM, Mobasher B. Effect of ground copper slag on strength and toughness of cementitious mixes. ACl Mater J 1999;96.

[40] Krottenthaler M, Schmid C, Schaufler J, Durst K, Göken M. A simple method for residual stress measurements in thin films by means of focused ion beam milling and digital image correlation. Surf Coat Technol 2013;215:247-52.

[41] Rossol MN, Shaw JH, Bale H, Ritchie RO, Marshall DB, Zok FW. Characterizing Weave Geometry in Textile Ceramic Composites Using Digital Image Correlation. J Am Ceram Soc 2013;96:2362-5.

[42] Yuan Y, Huang J, Peng X, Xiong C, Fang J, Yuan F. Accurate displacement measurement via a selfadaptive digital image correlation method based on a weighted ZNSSD criterion. Opt Lasers Eng 2014;52:75-85.

[43] Ghorbani R, Matta F, Sutton MA. Full-Field Displacement Measurement and Crack Mapping on Masonry Walls Using Digital Image Correlation. Adv. Opt. Methods Exp. Mech. Vol. 3, Springer; 2014, p. 187-96.

[44] Tominaga Y, Arikawa S, Yoneyama S, Fujimoto Y, Omoto Y. Observation of Thermal Strain on Electronic Packages Using Digital Image Correlation. Adv. Opt. Methods Exp. Mech. Vol. 3, Springer; 2014, p. 151-7.

[45] Das S, Kizilkanat A, Neithalath N. Crack propagation and strain localization in metallic particulatereinforced cementitious mortars. Mater Des 2015;79:15-25.

[46] Das S, Aguayo M, Sant G, Mobasher B, Neithalath N. Fracture process zone and tensile behavior of blended binders containing limestone powder. Cem Concr Res 2015;73:51-62.

[47] Gdoutos EE. Fracture mechanics: an introduction. vol. 123. Springer; 2006.

[48] Zhang P, Liu C, Li Q, Zhang T. Effect of polypropylene fiber on fracture properties of cement treated crushed rock. Compos Part B Eng 2013;55:48-54. 